\title{
Train Surveillance System Using Atmel At89c51 Microcontroller
}

\author{
Rajbir $^{1}$, Vedprakash $^{2}$, Akshit $^{3}$ \\ ${ }^{1,2,3}$ Department of ECE, Amity University Haryana, Gurgaon, India
}

\begin{abstract}
In this technical paper A Train Surveillance Model is designed to trace trains on their tracks using various sensors. This model is used to avoid train collisions and collision of other vehicles while crossing the railway track. This is technical paper is of further development and study to develop enhanced technologies for train surveillance and track switching.
\end{abstract}

Keywords: AGC, IR Sensor, Microcontroller ATMEL AT 89C51, TS,IR LED, COMPARATOR LM324

\section{Introduction}

Railway is one of the most widely used modes of transportation in India with more than 800 million people travelling by railway annually. Other than transportation Indian railway is also used to transport goods across the country with more than 950 million tonnes being carried annually. As above statistics show railway is of huge importance for Indian economy and GDP. Indian railway is the world's fourth largest rail network with thousands of railway stations. Being so complex and widely used mean of transport large number of accidents also take place resulting in loss of lives and wealth. Train accidents are majorly of two kinds two trains colliding with each other and collision with vehicles crossing the railway track. In India most of tracks are still manually controlled with station master giving the signals and tracks are changed manually. Even the signal to the road vehicles crossing the railway track are given manually. Many times the accidents take place due to human errors to eliminate these human errors this model has been developed in which the train signalling and monitoring is done automatically using microcontrollers and sensors. This eliminates the human errors and thus reduces the chances of railway accidents which dent the Indian economy.

\section{Automatic Gate Control}

A level occurs when a railway track is intersected by the road without bridge or tunnel. This is also called railway crossing or railroad crossing. In early times each level crossing had one flagman in a nearby booth who would control the road traffic by red and green flag, then came electrically closable gates which used to close the road when a train approached the crossing this was also controlled manually bya nearby booth. This project utilizes two IR trans-receiver pair; one pair of IR trans-receiver is fixed at one side of the railway gate and similarly the other pair is fixed at the other side of the railway gate.

\subsection{Block diagram of gate control:}

Whenever a signal from any of the trans-receiver is detected a buzzer sounded for say five seconds and then the gates are closed we will be using DC geared motor to open and close the gates. Now when the train is again detected at other IR trans-receiver the gates are opened. We are using L293 driver IC to control the motor i.e. open and close the gates. This type of gate control system can be used at all the unmanned level crossings across the country this will reduce the human errors and latency thus providing more safety and security at the level crossings. This system is completely based on microcontroller and quite economical.

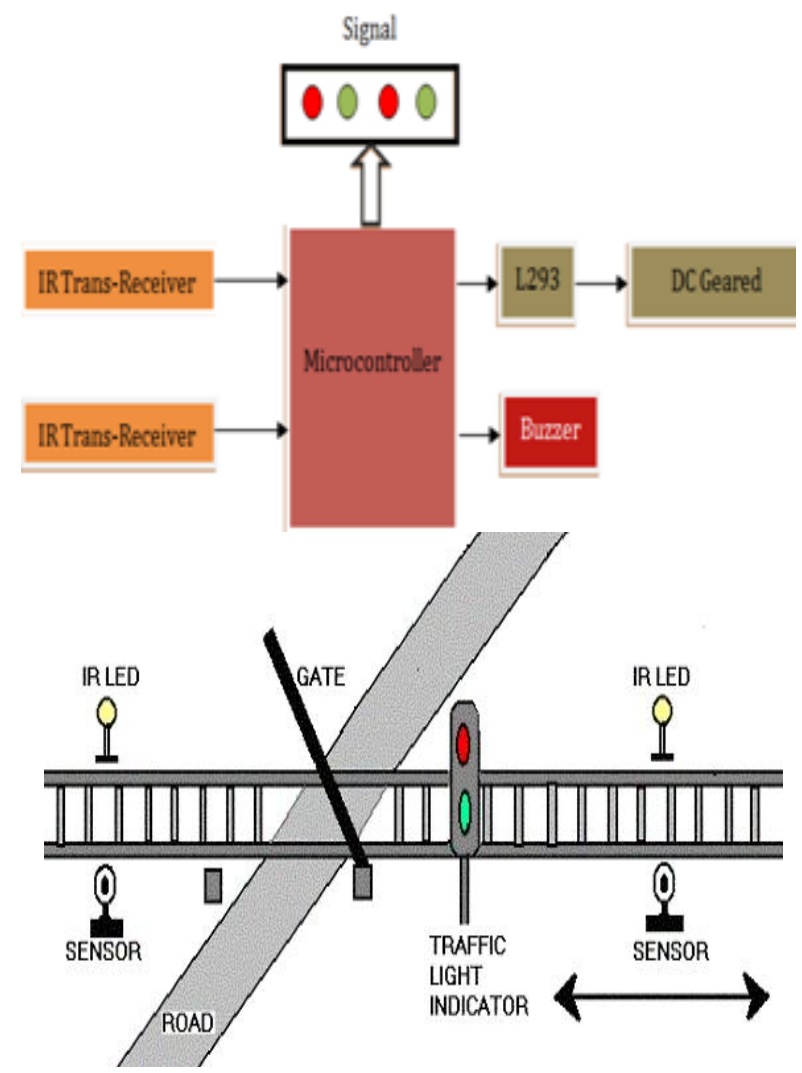

\section{Track Switching}

Using same the concept as in gate control we can switch the tracks of the train. This is needed when one train is standing on the platform and we need to provide another train say a superfast train. For this to happen in earlier times electromagnets were used. 


\section{International Journal of Science and Research (IJSR) \\ ISSN (Online): 2319-7064}

Index Copernicus Value (2013): 6.14 | Impact Factor (2015): 6.391

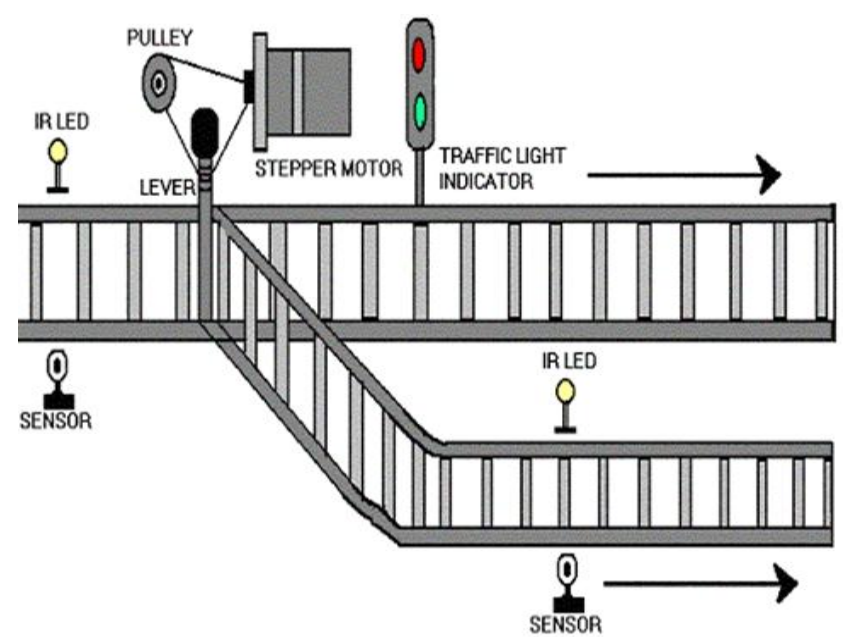

But now we can achieve this by using microcontroller and comparators LM324.

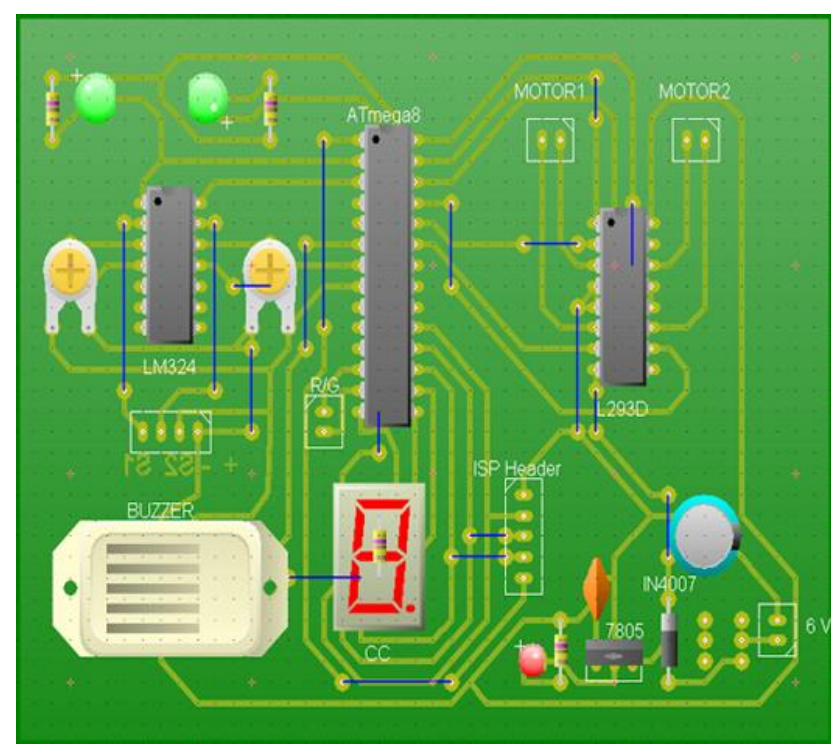

\section{Components}

Infrared Sensors: Infrared(IR) radiations are part of electromagnetic spectrum which also consists other radiations such as radio waves, visible light, microwaves, gamma rays, $\mathrm{x}$-rays and ultraviolet light.IR radiations lie between visible light and radio waves on the spectrum.

The basic working of IR sensors is that IR radiations are emitted by IR-LEDs and then reflected back by the object in front of the sensor. In this model we are using IR-LED to pick the reflected radiation which was emitted by the same type of LED.

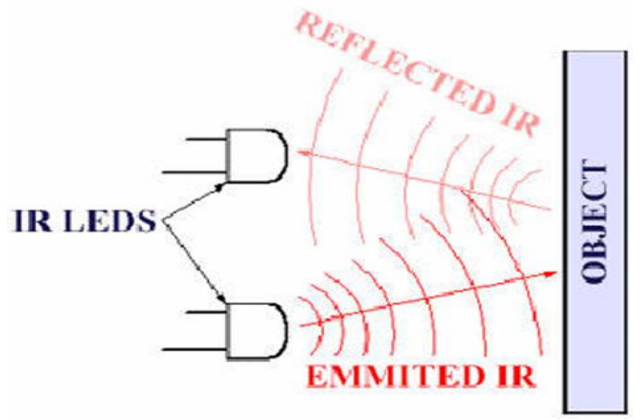

LDR: A Light dependent resistor or Cadmium Sulphide cell is a resistor whose resistance depends upon the intensity of the light. If the light falling on the resistor is having sufficient intensity then the photon is absorbed by the resistor which gives electrons enough energy to jump to the conduction band, the resulting free electron conducts electricity and thus reduces the resistance.

AT89C51 Microcontroller: This microcontroller consumes low power, it contains 4Kbytes of Flash programmable anderasable read only memory to provide high performance. Atmel AT89C51 microcontroller provides flexible and cost effective solution to various applications. The programme for the microcontroller is written in KEIL Software.

Stepper Motor: Stepper motor converts electrical energy into precise mechanical motion. The speed and angle of rotation of the stepper motor can be controlled very effectively so they have very use full application in various embedded systems. The stepper motor is controlled by the microcontroller using L293D, it is a motor driver integrated circuit which acts as current amplifier using the amplified current signals to drive the motors.

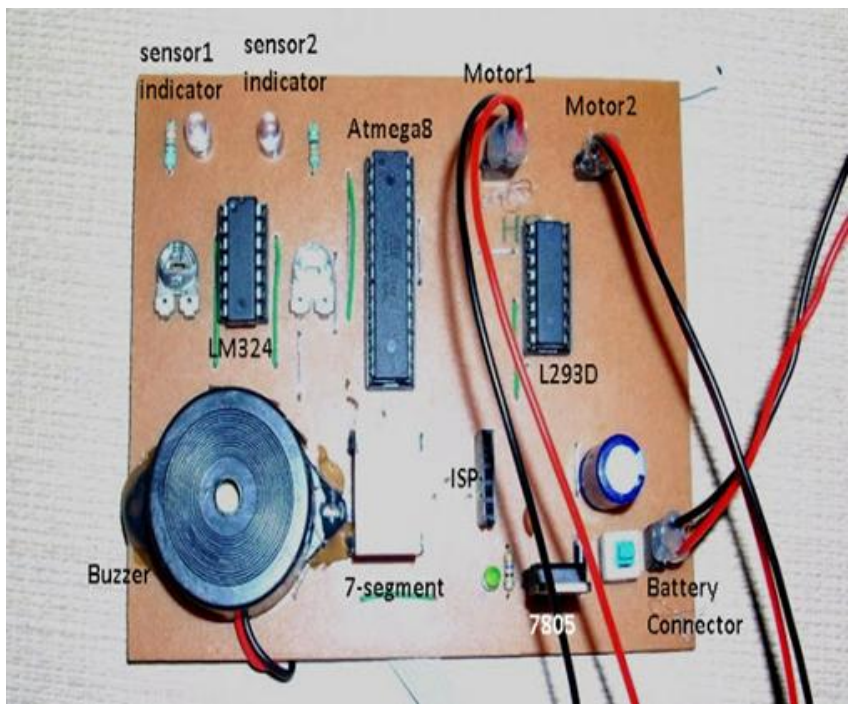

\section{Advantages Over Existing Methodology}

- Reduces chances of human error.

- Less time consuming.

- No need of human monitoring.

- Cost effective and less complex working.

\section{Limitations}

There are some limitations to this model of train surveillance firstly it requires various types of IR sensors which should not detect human interrupt. Secondly if at the time of gate closing if any vehicles get stuck in between the gates then it should be able to detect that and send the information to the microcontroller to take the requisite action.

\section{Future Improvements}

The limitations of this model has been discussed earlier which can be eliminated in future by further studies. The track switching can be made more specific by further studies and developments in which tracks can be allotted to more 


\section{International Journal of Science and Research (IJSR) \\ ISSN (Online): 2319-7064}

Index Copernicus Value (2013): 6.14 | Impact Factor (2015): 6.391

than two trains. The distance of detection of presence of other train on the track can be further increased with future discoveries.

\section{Conclusion}

The IR receivers should be properly working and should be checked regularly to avoid any kind of mishappening. The connections in the microcontroller should be neat and tight for proper working. All these things if taken care then the model provides its most efficient working and deliver safety and security. The time in which the gate will be closed after detection of the train at the level crossing should be displayed to the vehicles to provide more safety.

\section{Reference}

[1] Atmel AT89C51 Datesheet

[2] (2012) Kushagra, L293D, Engineers Garage, [Online]. Available: http://www.engineersgarage.com/electroniccomponents/l293d-motor-driver-ic

[3] Muhammad Ali Mazidi and Janice G. Mazidi, The 8051 Microcontroller And Embedded System, 2000, Pearson

Volume 5 Issue 6, June 2016 www.ijsr.net 